\title{
Stage I Lung Non-Small Cell Cancer AJCC v7
}

National Cancer Institute

\section{Source}

National Cancer Institute. Stage I Lung Non-Small Cell Cancer A/CC v7. NCI Thesaurus. Code C6671.

Stage I includes: IA: (T1a, N0, M0); (T1b, NO, M0) and IB: (T2a, N0, M0). T1a: Lung cancer with a tumor size of $2 \mathrm{~cm}$ or less $\mathrm{n}$ greatest dimension, surrounded by lung or visceral pleura and without bronchoscopic evidence of invasion more proximal than the lobar bronchus (i.e., not in the main bronchus). The uncommon superficial tumor of any size with its invasive component limited to the bronchial wall, which may extend proximal to the main bronchus, is also classified as T1a. T1b: Lung cancer with a tumor size more than $2 \mathrm{~cm}$ but $3 \mathrm{~cm}$ or less in greatest dimension, surrounded by lung or visceral pleura and without bronchoscopic evidence of invasion more proximal than the lobar bronchus (i.e., not in the main bronchus). T2a: Lung cancer with a tumor size more than $3 \mathrm{~cm}$ but 5 $\mathrm{cm}$ or less in greatest dimension. N0: No regional lymph metastasis. M0: No distant metastasis. (AJCC 7th ed.) 